\title{
Analysis of Wind Speed and Wind Pressure on the Facades in Frequency Domain for the Modelling of Air Change Rate
}

\author{
Krystyna Pietrzyk* \\ Chalmers University of Technology, Department of Architecture and Civil Engineering, 41296 Gothenburg, Sweden
}

\begin{abstract}
Air exchange in buildings is driven by pressure difference across the building envelope caused by wind and difference in density between external and internal air. The evaluation of the influence of wind on the air change rate is usually limited to the analysis of the hourly mean wind speed. Wind is a random phenomenon characterized by the broad energy spectrum. The high frequency part can be responsible for the oscillation of the air through the openings resulting in the increased air exchange. Wind pressure coefficient on the leeward site mostly depends on the form characteristics of the object in relation to wind direction. The analysis of wind speed and wind pressure on the facades in frequency domain can deliver interesting data to air change rate model. Some of the results of continuous measurements carried out on a single-family house for 8 months are presented in frequency domain. The statistics of wind speed, wind direction and pressure differences across the 6 building components are calculated. The wind turbulence and the pressure fluctuations on the facades and the roof of the building are being investigated using energy spectra of their signals. Farther analysis of the experimental results is needed to be able to include high frequency wind in the infiltration model.
\end{abstract}

\section{Introduction}

This paper is built upon the results of the work carried out over many years and constitutes a personal perspective/experience on the issue of probabilistic modelling of air exchange in buildings. The concept of evaluating the risk of poor air exchange was presented in [1]. The probabilistic model PROMO was developed over several years. The model was launched in $[2,3]$ and it was designated to estimate the probability of insufficient air exchange or excessive heat loss. The model allowed estimation of the effect of variations of climate conditions on air exchange in a building, but also on the building energy performance $[4,5]$. Probabilistic output in the form of probability density function of air change rate estimated with the help of FORM (first-order reliability method) using the program developed by Czmoch [6] formed a ground for reliability analysis of adequate ventilation. The model was applied to analyze the hourly air exchange caused by air infiltration in a building situated near Gothenburg. Contributions of both wind and temperature difference were evaluated. Model was validated based on the results of pressure difference measurements through the building envelope. This work has been extended in [7] by including the combined effect of infiltration and mechanical ventilation, both exhaust and balanced. In [8] the concept of risk/reliability evaluation of building/environment system performance was proposed as the part of the broader approach concerning reliability analysis in building physics design. Requirement for the system specified in the form of performance criterion had usually been treated as a deterministic value. In [9], a stochastic threshold criterion for air change rate was introduced and discussed. Sensitivity analysis of the influence of wind and outdoor temperature on the air infiltration tested the model outcome in terms of its robustness in the presence of uncertainty. It was first presented on the IEA Annex55 meetings and then published at the conferences in $2012 / 2013$. The probabilistic risk analysis along with the effective tools for sensitivity analysis is proposed to be used to support design decisions and to develop better models for evaluation of building performance [10]. The work presented in actual paper concentrates on the possibility to consider the higher frequency of wind conditions in the air exchange model based on wind pressure measurements. The importance of considering wind-driven pressure fluctuations on the building envelope in air infiltration model sis acknowledged in $[11,12]$.

Wind is a stochastic phenomenon that is influenced by the surface roughness of the ground. The impact of wind on air exchange in buildings depends on permeability and the geometry of a building envelope and is usually discussed in relation to hourly wind speed. However, broader wind energy spectrum describing the turbulent part of wind speed could be analyzed and considered in the model of air change rate. Air exchange models applied in practice do not include the unsteady flow effects. One of the reasons is the unavailability of data [13]. A very extraordinary measurement program was carried out on the detached house near to Gothenburg where the

\footnotetext{
* Corresponding author: krystyna.pietrzyk@chalmers.se
} 
fluctuating characteristics of turbulence were measured with sampling frequency f $20 \mathrm{~Hz}$ and expressed by reduced power spectrums of wind speed and wind and temperature governed pressure differences across building components. Unsteadiness arising from external wind gustiness and that generated by surface wind pressures will be investigated to be included in the model of wind induced infiltration based on the one proposed in [2]. The original model refers to low-rise building with light-weight construction, single ventilation and temperature zone, and steady-state conditions of air flow. The simple quadrature LBL infiltration model was applied. Air change rate, wind speed and direction, temperature, pressures and leakage characteristics were all treated as the random variables. The $\mathrm{ACH}$ probabilistic distribution was estimated, and the risk of inadequate ventilation was evaluated. It is planned to introduce the rapidly varying fluctuations of wind speed to the model.

\section{Modelling of air infiltration}

\subsection{Wind properties}

Air exchange in buildings is driven by pressure difference across the building envelope caused by wind and difference in density between external and internal air. The evaluation of the influence of wind on the air change rate is usually limited to the analysis of the hourly mean wind speed. However, wind is a random phenomenon characterized by the broad energy spectrum shown in Figure 1. The high frequency part can be responsible for the oscillation of the air through the openings resulting in the increased air exchange.

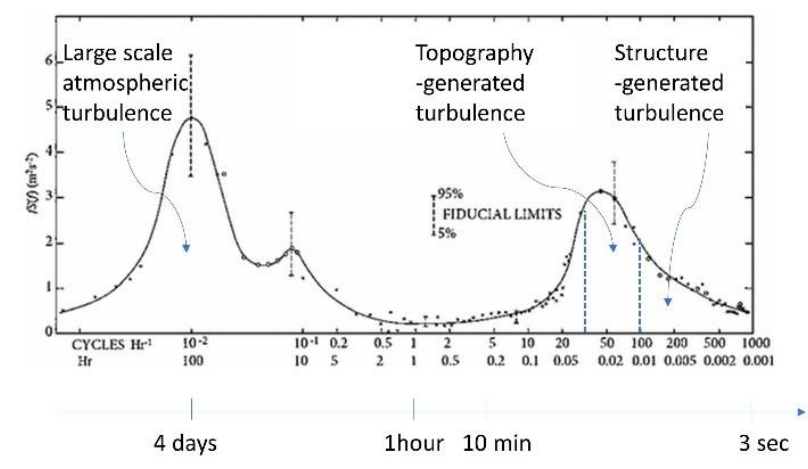

Fig. 1 Wind speed spectrum (modified from [14] and [15])

The wind speed would then be described by the annual mean wind velocity, the 10-minute mean similar to the hourly mean wind speed (slow fluctuations), and the rapidly fluctuating component referring to the influence of the large-scale turbulence of wind caused by the atmospheric wind flowing over hills and rough terrain, etc., and to the turbulence locally generated by the building structure.

According to Handa et al [16], the pressure fluctuations give rise to both laminar and turbulent flow through leakages. High-frequency fluctuations create a turbulent distribution of air through the opening comprising eddies with dimensions comparable to, or less than, the size of leaks. Certainly not all pressure fluctuations are fully transmitted through the envelope taking part in the air exchange.

\subsection{Wind driven air exchange}

The concept of the wind induced air change rate $\mathrm{ACH}$ $(1 / h)$ has been expressed by the following equation describing air change rate caused by wind blowing from direction sector $\mathrm{d}(\mathrm{d}=1$ to 8$)$ at the time $t$ calculated for different components exposed to either a positive pressure difference (inward flow) or to negative pressure difference (outward flow) [2]:

$$
\begin{gathered}
A C H_{d}(t)=\left(\frac{3600}{V}\right) \sum_{j=1}^{n}\left(K_{d, j}\left(v_{q}\right)\right) A_{j} \\
{\left[0.5 \rho\left(C p_{d, j}^{\text {ext }}-C p_{d, j}^{\text {int }}\right) v_{d}^{2}(t)+0.04 z_{j} \Delta T(t)\right]^{0.5}}
\end{gathered}
$$

where: $K_{d, j}$ - a leakage function presented as a linear function of $\mathrm{v}_{\mathrm{q}}$ relating the flow rate through the openings to the area of building component $j$ and the corresponding pressure drop across openings for wind blowing from sector $\mathrm{d}\left(\sqrt{\mathrm{m}^{3} / \mathrm{kg}}\right) ; \mathrm{v}_{\mathrm{q}}$ - "frictionless flow velocity" through the openings $(\mathrm{m} / \mathrm{s}) ; \mathrm{n}$ - number of elements of the envelope of a building facing only positive or only negative pressure difference; $\mathrm{V}$ - volume $\left(\mathrm{m}^{3}\right) ; \mathrm{A}_{\mathrm{j}}$ - area of $\mathrm{j}$-th element $\left(\mathrm{m}^{2}\right) ; \rho$ - air density $\left(\mathrm{kg} / \mathrm{m}^{3}\right) ; C p_{d, j}^{\text {ext }}$ external pressure coefficient assumed for the façade $\mathrm{j}$ exposed to wind from the direction $\mathrm{d}(-) ; C p_{d, j}^{\text {int }}$ - internal pressure coefficient assumed for the façade $\mathrm{j}$ exposed to wind from the direction $\mathrm{d}(-) ; \mathrm{v}_{\mathrm{d}}(\mathrm{t})$ - wind blowing from direction $\mathrm{d}(\mathrm{m} / \mathrm{s}) ; \mathrm{z}_{\mathrm{j}}$ - vertical distance from the neutral pressure layer to the centre of the $\mathrm{j}$-th building element $(\mathrm{m}) ; \Delta \mathrm{T}(\mathrm{t})-10$-min mean temperature difference between outside and inside $(\mathrm{K})$ treated later on as slowly changing one-hour mean.

Wind velocity from a certain direction $d$ as well as the pressure differentials across the envelope can be treated as the random variables represented by slowly and rapidly varying fluctuations given in the frequency domain by reduced power spectra. The spectrum of a wind speed contains essential information about the nature of wind, the type of upwind landscape and the geometry of the building structure.

Frequency domain analysis is used to characterize the wind energy distribution among the frequency intervals. The power spectrum is generated by using a discrete Fourier transform. The reduced power spectrum of wind speed is given by the following equation:

$$
f S_{v}(f) / \sigma_{v}^{2}
$$

where: $\sigma_{\mathrm{v}}-$ standard deviation for the wind speed fluctuations; f-frequency; $S_{v}(f)$ - power spectrum of the wind speed for the frequency $f$.

Pressure fluctuations caused by wind turbulence have an influence on the air flow through the openings and cracks in the building envelope. The character of the flow depends on the geometric characteristics of the leakages in relation to the length scale of wind and the Reynolds 
number of the air flow. As it is written in [17], the fluctuations of the external pressure above certain frequency given in as $0.53 \mathrm{~Hz}$ for a nominally sealed engineered building are attenuated and do not influence the air exchange.

Generally, the transfer function $H$ (see Equation 3) would be of interest where $\mathrm{S}$ is a power spectrum.

$$
S_{A C H}(f)=|H(f)|^{2} S_{v}(f)
$$

The transfer function could describe the frequency related air exchange through the openings' characteristic for the windward surface. The properties of wind driven flow including topography and structure generated fluctuations would contribute to the effect of infiltration.

\section{Case study}

\subsection{Description of the building}

The house was constructed in 1979 with the intention of using it for experimental studies in building physics with focus on ventilation and energy saving. The garage with doors facing south is in the extended south part of the concrete cellar as shown in Figure 2.

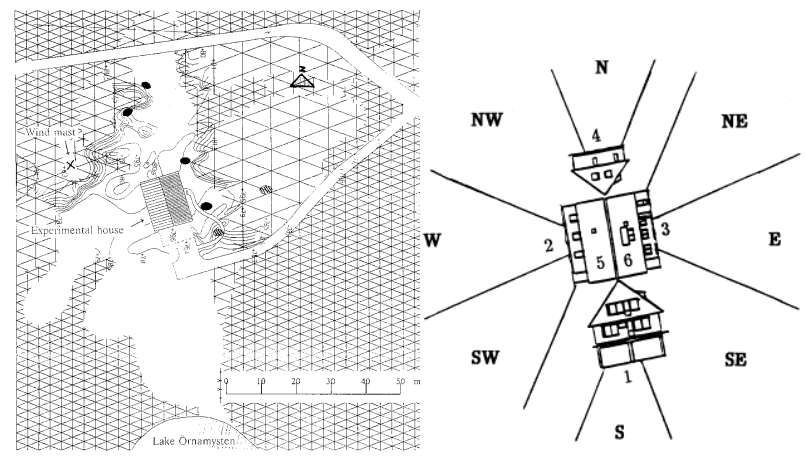

Fig. 2 Situation of the building against wind directions and the elements of topography and vegetation

According to the map of the nearest surroundings given in Figure 2, the house is located about 11 degrees from the north-south direction. There is a small lake about $100 \mathrm{~m}$ from the building to the south. To the east and north-west of the house there are two small hills. The house is surrounded by trees of different height. To the south-west very tall pine trees give shelter to the building.

\subsection{Measurements}

A special measurement and data analysis system using Turbo Pascal numerical methods Toolbox was developed by Schechinger [18]. The following parameters have been measured: (1) leakage characteristics of the house using blower door tests, (2) pressure differences across the six building components with Validyne pressure transducers, (3) wind speed and wind direction with the anemometer located on a small hill about $25 \mathrm{~m}$ from the house, (4) internal and external temperatures, (5) internal and external relative humidity, (6) 30 measurements of $\mathrm{ACH}$ at various locations in the building using tracer gas. The measurement program had been carried out for 8 months. As a result, every hour, 10-min mean data and reduced power spectra and cross spectra of 3-second wind speed and pressure differences across the building components were registered.

For the measurement of pressure distribution across the walls and roof, $25 \mathrm{~m}$ long plastic tubes were connected between the measuring points and the Validyne pressure transducer. As mentioned earlier, twelve measuring points uniformly distributed over a surface (see Figure 4) were connected to a single pressure transducer through a connector as described in [19]. The plastic tubes entered the house at the same level and were placed behind the external cladding in a temperature close to the external one. The pressure transducers were placed in the measurement room located in the basement as shown in Figure 3. The measured pressure difference data have been recalculated to the level characteristic for every surface (the height of the central point of the component).

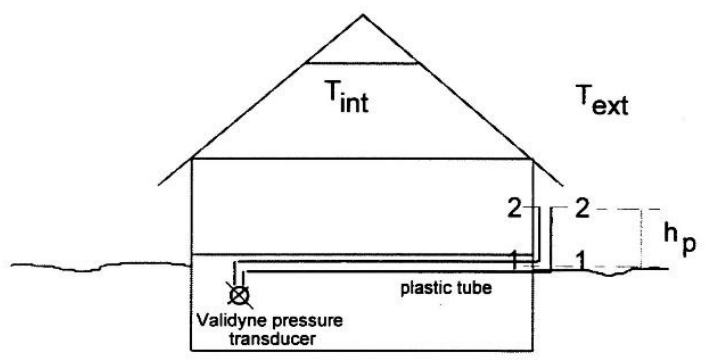

Fig. 3 Measurement technique applied to obtain pressure differences across the building envelope (the south façade)

The setup of the measurements was critically analyzed. In [19] one reads "The dynamic influence of the pressure tubes and the 12-to-1 tube connector has been studied. Gustén \& Magnusson in [20] investigated the influence of the length of the plastic tubes on the response characteristics of the system. They tested tubes with $25 \mathrm{~m}$ length, $50 \mathrm{~m}$ length and $115 \mathrm{~m}$ length. They concluded, that with increasing length of the tubes the spectrum was increasingly distorted, with the distortion starting at ever lower frequencies. However, for the case of the $25 \mathrm{~m}$ tubes, the distortion was within $+/-20 \%$ up to some $3 \mathrm{~Hz}$. The influence of the 12-to-1 tube connector has been studied in [21]. Comparison of the mean of 6 signals measured independently for each of the 6 tubes with the mean of 6 signals obtained by measuring a single channel with the 12-to-1 connector revealed differences starting already below $0.1 \mathrm{~Hz}$ and increasing over the range up to $1-2 \mathrm{~Hz}$. The difference was, though, in the range of $10 \%$."

The wind and the pressure difference across the facades were analyzed by employing spectral methods to extract the statistical parameters and to investigate the influence of wind pressure fluctuations on the air exchange. However, only10-min mean data were used to build up and validate the probabilistic model of air infiltration and heat loss in low-rise buildings [2]. High frequency fluctuations were not examined. Now, the limited number of spectra sampled with $20 \mathrm{~Hz}$ frequency has been converted to the ascii format for the preliminary analysis. They are presented in the following section. It 
has been important to see if it is still possible to read the material recorded 30 years ago and obtain the data of acceptable quality.
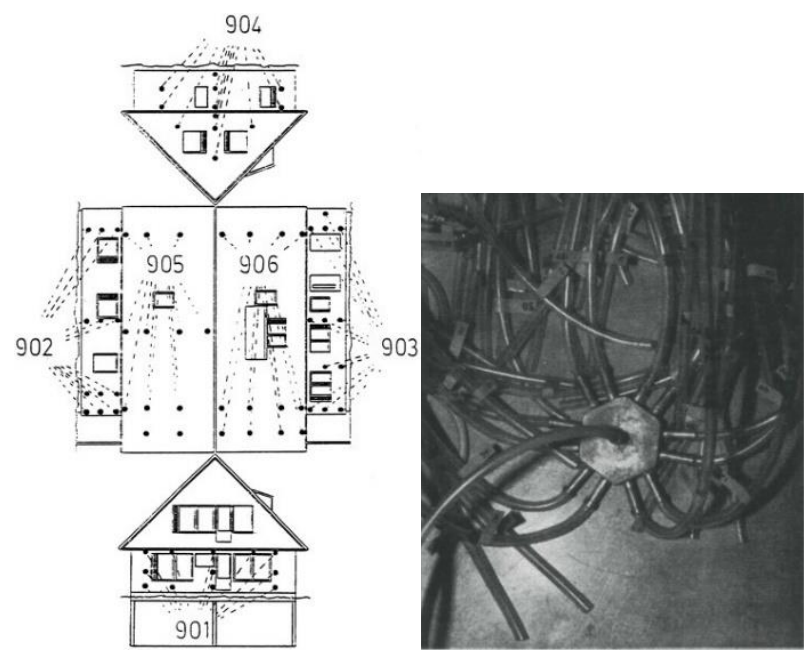

Fig. 4 a) Distribution of the wind pressure measurement's points on the building envelope; b) 12-1 tube connector.

\subsection{Results}

The reduced power spectra of wind speed and the ones of pressure differences will be examined to support modelling of the impact of wind fluctuation on the air change rate. Some examples are presented below
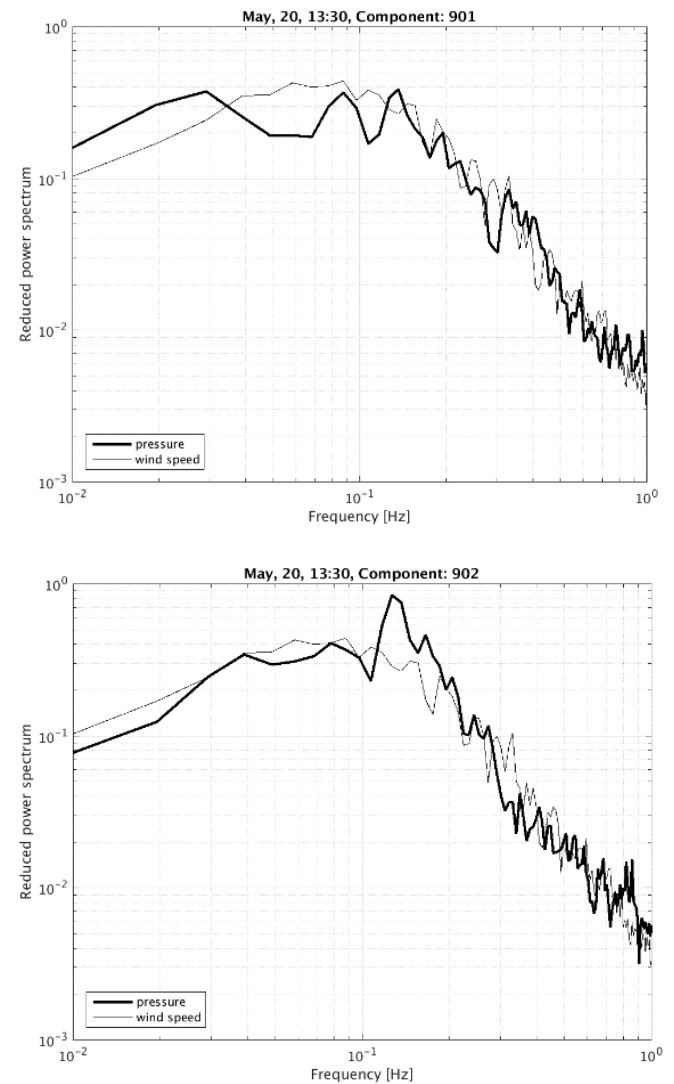
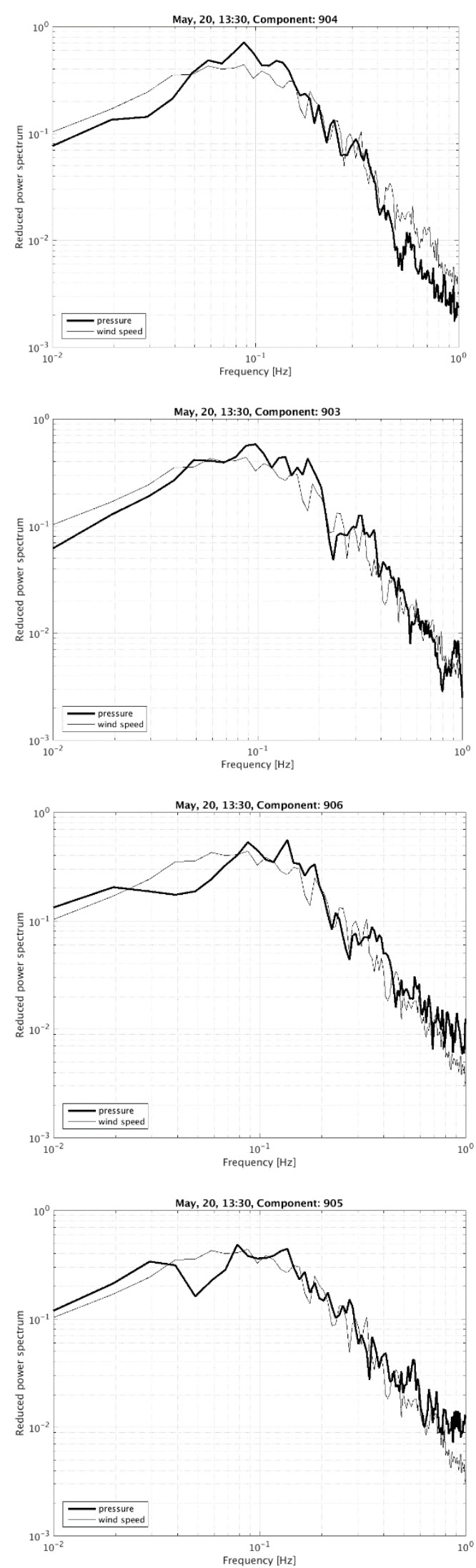

Fig. 5 The reduced power spectra of the pressure differences across the 6 components - bold line, (see Fig.4a): 901(façade S), 902 (façade W), 903 (façade E), 904(façade N), 905 (roof W), 906 (roof E) together with the wind speed reduced power spectrum - normal line 
The cases with higher wind speed have been chosen to marginalize influence of convective turbulence. Figure 5 shows the 10-min spectra of the 6 components' pressure differences together with the wind speed spectrum $\left(\mu_{\mathrm{v}}=4.76 \mathrm{~m} / \mathrm{s}\right)$. The spectra obtained for the windward component (902 in Figure 4a) and the upwind speed (W) look similar.

The reduced power spectra of wind speed and the ones of pressure differences will be examined to support modelling of the impact of wind fluctuation on the air change rate. Some examples are presented below. The cases with higher wind speed have been chosen to marginalize influence of convective turbulence. Figure 5 shows the 10-min spectra of the 6 components' pressure differences together with the wind speed spectrum $\left(\mu_{\mathrm{v}}=4.76 \mathrm{~m} / \mathrm{s}\right)$. The spectra obtained for the windward component (902 in Figure 4a) and the upwind speed (W) look similar.

The set of reduced power spectra of pressure differentials calculated for the 6 building components for the one 10-min period for wind blowing from the South $(\mu \mathrm{v}=6.77 \mathrm{~m} / \mathrm{s})$ is shown in Figure 6 . The big opening under the garage door is situated from the south site of the building (see Figure 2). It seems that it influences the pattern of the pressure differential spectrum across the windward façade.
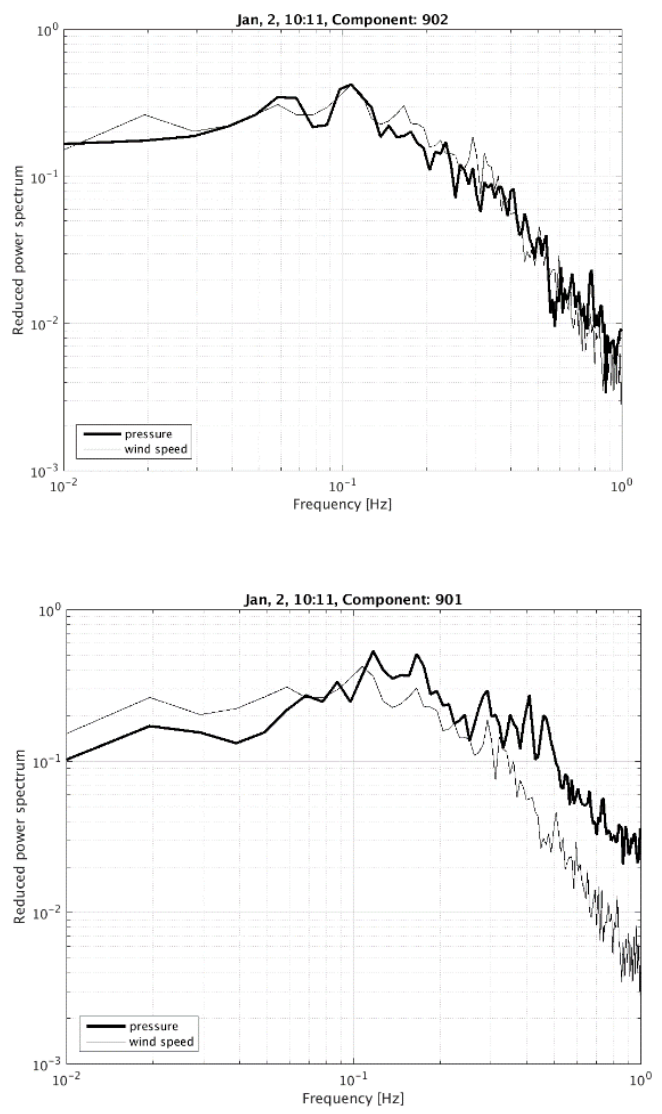
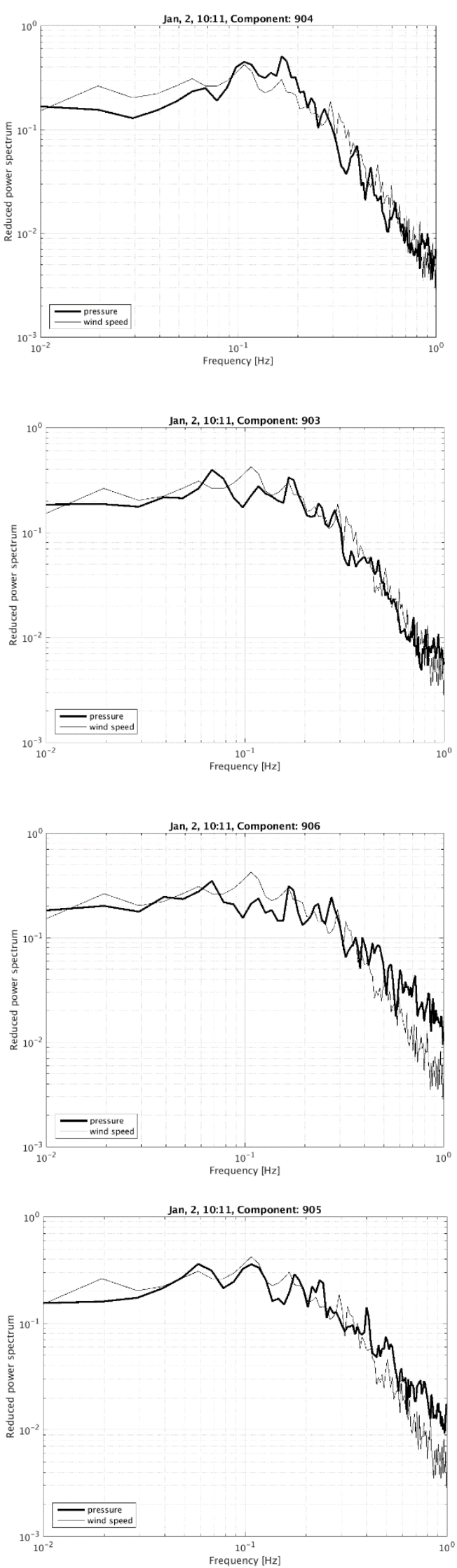

Fig. 6 The reduced power spectra of the pressure differences across the 6 components - bold line, (see Fig.4a): 901(façade S), 902 (façade W), 903 (façade E), 904(façade N), 905 (roof W), 906 (roof E) together with the wind speed reduced power spectrum - normal line 
The examples show the differences between the shapes of the individual pressure spectra. They depend mainly on the positions of the components against the wind direction and the types of openings/leakages at the building envelope. The spectra of pressure differences across the roof components show more power in the interval of higher frequencies. Generally, the greater part of the spectrum for both examples can contribute to air infiltration.

The 10-min and the 3-s means, and standard deviations of wind speed and wind pressure differentials on windward facades are listed in Table 1 and Table 2.

Table 1. Mean value $\mu$, standard deviation $\sigma$, coefficient of variation $\sigma / \mu$, of $\mathrm{v}-10$-min wind speed, $\mathrm{v}_{3} \mathrm{~s}-3 \mathrm{~s}$ wind speed

\begin{tabular}{|l|l|l|l|l|l|}
\hline $\begin{array}{l}\text { Wind } \\
\text { dir. }\end{array}$ & $\begin{array}{c}\mu_{v} \\
10-\text { min }\end{array}$ & $\begin{array}{c}\sigma_{v} \\
10-\min \end{array}$ & $\frac{\sigma_{v}}{\mu_{v}}$ & $\mu_{v 3 s}$ & \\
\hline $\mathrm{N}$ & 2.27 & 0.97 & 0.43 & 0.91 & 0.47 \\
\hline $\mathrm{E}$ & 2.89 & 1.09 & 0.38 & 0.96 & 0.45 \\
\hline $\mathrm{S}$ & 2.23 & 1.01 & 0.45 & 0.90 & 0.41 \\
\hline $\mathrm{W}$ & 2.19 & 1.13 & 0.52 & 1.00 & 0.59 \\
\hline
\end{tabular}

Table 2. Mean value $\mu$, standard deviation $\sigma$, coefficient of variation $\sigma / \mu$, of $\mathrm{v}$ - wind speed, $\Delta \mathrm{p}_{3 \mathrm{~s}}-3 \mathrm{~s}$ pressure difference between the outside and the inside of the building

\begin{tabular}{|l|c|c|c|c|}
\hline $\begin{array}{l}\text { Wind } \\
\text { dir. }\end{array}$ & $\begin{array}{c}\mu_{\Delta p 3 s} \\
\text { windward }\end{array}$ & $\begin{array}{c}\sigma_{\Delta p 3 s} \\
\text { windward }\end{array}$ & $\frac{\sigma_{\Delta p 3 s}}{\mu_{\Delta p 3 s}}$ & $\frac{\sigma_{v}}{\mu_{v}}$ \\
\hline $\mathrm{N}$ & 1.45 & 1.24 & 0.86 & 0.43 \\
\hline $\mathrm{S}$ & 1.09 & 1.06 & 0.97 & 0.45 \\
\hline
\end{tabular}

Coefficient of variation $\sigma / \mu$ of 10 -min as well as of 3 $\mathrm{s}$ mean wind speeds are of the same size. Coefficients of variations of the rapid fluctuations of the pressure differentials across the windward facades are higher than those of wind speed. This can be important in the process of the air exchange.

\section{Conclusions}

- A short overview of the personal contribution of the author to the field of the probabilistic modelling of air exchange in buildings is given. It is proposed to extent the probabilistic model of air exchange in buildings described in [2] to include rapid pressure fluctuations on the air change rate based on the spectral data.

- The analysed spectra of the windward wall pressure differences together with the relevant upwind speed spectra show similar forms. The greater part of the spectrum could contribute to the air exchange. High coefficients of variations of the rapid fluctuations of the pressure differentials across the windward facades might be important for the air exchange.

- The examples show the differences between the shapes of the individual pressure spectra. They depend mainly on the positions of the components against the wind direction and the types of openings/leakages at the building envelope. The mean values of reduced power spectra for the specified wind speed and direction across each component will be further studied.
- The results of wind and pressure differential fluctuations for the whole measurement period should be converted to the ascii format for further analyses of the different/typical patterns of theirs power spectra

- Degree of coherence between fluctuating wind speeds and fluctuating pressure differences between outside and inside of the building will be further examined.

The author is grateful to Kamal Handa who formulated and initiated the project. The financial support provided by Swedish Council for Building Research for the measurement program is gratefully acknowledged. The author thanks Adlerbertska Foundation for financing the analysis of the results.

\section{References}

1. K. Pietrzyk, Scan. Forum for Stoch. Mech, University of Aalborg, Denmark (1991)

2. K. Pietrzyk, Ph.D thes. Chalmers U. of Tech. (2000)

3. K. Pietrzyk, C.-E. Hagentoft. Building and Environment. 43/4, 537-549 (2008)

4. K. Pietrzyk, C.-E Hagentoft. Buildings $I X$, ASHRAE, Florida, USA (2004)

5. K. Pietrzyk, J. of Build. Phys. 34, no.1, 77-96 (2010)

6. I. Czmoch. PhD thesis, Luleå University of Technology, Sweden (1998)

7. K. Pietrzyk, The Int. J. of Vent. 4, 2 143-156 (2005)

8. K. Pietrzyk, C.-E. Hagentoft, Building and Environment. 43/4, 558-568 (2008)

9. K. Pietrzyk the 8th Nordic Symp. on Build. Phys., Copenhagen, Denmark, 1 401-409 (2008)

10. K. Pietrzyk, I. Czmoch, Risk Assessment, ed. Valentina Svalova, IntechOpen (2018)

11. F. Haghighat, J. Rao, P. Fazio. Building and Environment, 26, no. 2, 95-109. (1991)

12. F. Haghighat, H. Brohus, J. Rao, Building and Environment, 35, 377-385 (2000)

13. D. Etheridge, Build. and Enviro. 35, 321-337 (2000)

14. I. Van der Hoven J Meteorol 14:160-164 (1957)

15. J. Gustén Ph.D Chalmers Univ. of Tech. (1989)

16. K. Handa, G. Kärrholm, T. Lindquist. BFR, Report T3, Stockholm (1979)

17. J.D.Ginger, K.C. Mehta, B.B. Yeatts. J. of Wind Eng. and Ind. Aerodynamics 72,163-174 (1997)

18. B. Schechinger. Chalmers University of Technology, Build. Aerodyn. Res. Gr., Rep. (1991)

19. B. Schechinger. Chalmers University of Technology, Build. Aerodyn. Res. Gr., Rep. (1993)

20. J. Gustén, B. Magnusson Chalmers Univ. of Tech., Div. of Struct. Design, Rep. 5 (1986)

21. A. Pietrzyk. Chalmers U. of Tech. Div. of Struct. Design, Rep. 4 (1993) 